\title{
Embriones y procreación asistida ante los tribunales europeos: remisión a la decisión de los jueces nacionales*
}

\author{
Elisabetta Catelani \\ Catedrática de Instituciones de Derecho Público \\ Universidad de Pisa
}

Recibido: 02.05.12

Aceptado: 31.05 .12

Resumen: En este trabajo, se hace referencia a la determinación por parte de la doctrina y jurisprudencia Europea del tratamiento de embriones humanos para fines científicos, terapéuticos y de diagnóstico. Se hace mención de la jurisprudencia más relevante al respecto.

Palabras clave: embriones humanos, Corte Europea de Derechos Humanos, jueces, reproducción asistida.

Abstract: This paper refers to the determination by the European doctrine and jurisprudence of the legal treatment of human embryos for scientific, therapeutic and diagnostic purpose. Also its mention the more relevant jurisprunce regarding this subject.

Key words: human embryos, European Court of Human Rights, judges, assisted reproduction.

Hace ya algún tiempo la doctrina italiana y europea generalmente se ocupa del tema de la tutela multinivel de los derechos fundamentales y de la necesidad de configurar los derechos constitucionales en una visión "abierta". Este camino no parece viable, sin embargo, con respecto a todos los derechos, en particular allí donde existen cuestiones morales y éticas delicadas, con respecto a los cuales los Estados miembros deben poder gozar de un amplio margen de discrecionalidad.

La cuestión del tratamiento de embriones humanos para fines científicos, terapéuticos y de diagnóstico, así como la del régimen de la reproducción asistida se deja, al parecer, a la decisión de los Estados individuales o incluso a la decisión interpretativa de los jueces individuales.

En estas pocas observaciones querría intentar verificar si la dirección que están tomando los tribunales europeos, seguidos luego por el Tribunal Constitucional italiano en una decisión sobre la cuestión de la reproducción asistida, determina, como consecuencia inevitable una disciplina diferenciada de tales aspectos en los diversos Estados, en virtud de la autonomía y la libertad

* Traducción de Carlos Vidal Prado (UNED) 
de decisión que cada uno de ellos debe tener, o si realmente es posible concretar una dirección unitaria, al menos sobre algunos aspectos.

Es necesario por tanto determinar si, con respecto al caso en cuestión, existe una justa ponderación entre las legítimas instancias de tutela que cada Estado puede reivindicar para la protección de los intereses generales y de valores percibidos como fundamentales en un determinado momento histórico y la protección de derechos individuales.

Sobre estos aspectos es necesario hacer referencia a tres decisiones que pueden ser consideradas como emblemáticas para comprender la orientación que están tomando los tribunales europeos e italianos: la sentencia Brüstle de 18/10/11 del Tribunal de Justicia de Luxemburgo, la sentencia de 03/11/11 del Tribunal Europeo de Derechos Humanos de Estrasburgo y por último la Ordenanza núm. 150 de la Corte Constituzionale italiana de 22 de mayo de 2012.

Amplia fue la discusión sobre el contenido de la sentencia Brüstle durante nuestro seminario italo-español y, en particular se puso en evidencia cómo el Tribunal de Luxemburgo, entre los diversos aspectos afrontados, ha remitido a los jueces nacionales individuales la valoración de las posibilidades de que las células sean o no consideradas "embrión humano", a la vista de los avances en la ciencia. Al mismo tiempo en dicha decisión fue reafirmado el principio fundamental de derecho de la Unión, según el cual si la norma europea "no contiene ninguna referencia explícita al derecho de los Estados miembros", debe interpretarse de forma independiente y uniforme a nivel europeo.

Dos principios aparentemente contradictorios entre ellos que ponen sin embargo en evidencia el problema de fondo quizá presente en Europa: por un lado la necesidad de garantizar un sistema integrado de derechos fundamentales y de ampliar en la medida de lo posible la interpretación y aplicación uniforme de los derechos en espacio único europeo, por otro lado, sin embargo, la oportunidad de asegurar un margen de discrecionalidad a los Estados miembros allí donde están en discusión cuestiones morales y éticas.

Este principio es confirmado y reiterado en la sentencia del Tribunal de Estrasburgo de 3 de noviembre de 2011 que ha abordado un tema tan sensible desde el punto de vista de los valores morales y sociales en juego, constituido precisamente por el tratamiento de la procreación médicamente asistida de tipo heterólogo. La Gran Sala, en la presente decisión, ha reformado la sentencia adoptada previamente por el TEDH (Sala Primera) el 11 de marzo de 2010, declarando que no había habido ninguna infracción del art. 8 en relación con lo dispuesto por el art. 14 de la CEDH por parte de la legislación austriaca, en la que está prohibida la donación de óvulos y esperma de tipo heterólogo para la fecundación in vitro. Varios son los aspectos que se tratan en esta sentencia, pero lo que específicamente se destaca por la Gran Sala (ya señalado por lo demás en la sentencia de la Sala Primera) es la falta de un "enfoque uniforme" por parte de los Estados contratantes y la "naturaleza delicada de las cuestiones morales y éticas en cuestión", de modo que los Estados partes 
tienen en este campo un margen de discrecionalidad particularmente amplio. Un margen tan grande que permite a la Gran Sala afirmar que el legislador austríaco, al regular la reproducción asistida no se ha excedido en su uso.

El amplio espacio que se pretende reconocer a los Estados en estos aspectos se ve confirmado, según el Tribunal de Estrasburgo, también por el hecho de que la legislación en los 39 países del Consejo de Europa es muy diversa y que las soluciones que están previstas para proteger estos intereses en juego son igualmente variadas. También se hace mención a la Directiva 2004/23/CE sobre el tema de las células y tejidos humanos, en la que se excluye la posibilidad de que dicha norma pueda interferir en las decisiones de los Estados miembros sobre el uso o no uso de determinados tipos de células humanas y todavía menos pueda entrar en conflicto con sus disposiciones destinadas a definir el término jurídico "persona" o "individuo".

También en esta sentencia, por tanto, el Tribunal Europeo no pretende superponerse a los Estados o, mejor, a la dirección política (incluso aunque fuese) de naturaleza moral y ética que en ese momento histórico el legislador considera que debe perseguir. Esto no impide a la Gran Sala observar, en sus conclusiones, que el Parlamento austriaco, así como todos los Estados partes, deberán tener en cuenta de un modo más profundo la evolución de la ciencia y la sociedad al respecto, pero esto no permite en cualquier caso al juez europeo poder interferir en el equilibrio interno entre los intereses públicos y privados afectados en el contexto social que ha conducido a la adopción de la legislación austriaca impugnada. Si por un lado el deseo hacia una siempre mayor armonización entre las legislaciones de los Estados europeos representa un principio básico y un camino común a recorrer, al mismo tiempo no podemos todavía afirmar que este objetivo deba perseguirse incluso contra los principios que el Estado considera superiores en ese momento.

La Ordenanza de la Corte Constituzionale italiana tiene su origen precisamente en el contenido de la decisión de la Gran Sala porque, para abordar la legitimidad constitucional de la Ley italiana de reproducción asistida (Ley $\mathrm{N}^{\mathrm{o}} 40 / 2004$ ) y en particular la prohibición de la fecundación heteróloga en ella prevista, ha invocado el contenido de la decisión del Tribunal de Estrasburgo, remitiendo las actuaciones a los jueces a quibus.

Esta decisión puede interpretarse como una simple remisión para evitar, aunque sólo temporalmente, divisiones internas en la Corte sobre cuestiones morales que ponen en juego, además de principios jurídicos, valores morales y conciencia, no fácilmente separables entre ellos. Salvo que luego se pueda considerar la posibilidad de que el Tribunal pueda llegar, en un momento posterior, con una motivación más adecuada de los términos y motivos de la cuestión, también a la luz de los espacios que dejó abiertos el TEDH, a una declaración definitiva de inconstitucionalidad.

Se puede, sin embargo, también considerar la decisión de la Corte sólo una interlocución con carácter provisional, pero que en realidad pone fin a la duda de constitucionalidad, en cuanto que la Corte considere la evaluación 
de la amplitud del margen de apreciación de los Estados que el TEDH ha subrayado en repetidas ocasiones con relación a estos aspectos. Precisamente porque están en juego valores morales y éticos el Tribunal Constitucional tiene espacio para considerar lícita la atribución de un valor preeminente a los derechos del nasciturus, antes que al de los padres a procrear a través de caminos distintos al del tratamiento omólogo.

Por supuesto hay que tener en cuenta que una legislación italiana completamente diferente de la seguida por todos los demás Estados de Europa, a la larga, podría llegar a no considerarse dentro del margen de discrecionalidad, especialmente si el llamado "turismo procreador" conlleva una fuerte diferencia de tratamiento en comparación con los otros ciudadanos de los otros 27 y/o 36 Estados europeos. Pero hasta que no se conforme este convencimiento común, los Estados serán libres para atribuir un reconocimiento diferente a los valores de dignidad del ser humano.

Los tribunales europeos por otro lado han afirmado a menudo que las tradiciones sociales y culturales de los Estados miembros pueden constituir un límite a un tratamiento uniforme entre ellos.

En última instancia la europeización de los derechos no significa también la europeización de todos sus valores. 